\title{
Comparative performance of invasive alien Eichhornia crassipes and native Ludwigia stolonifera under non-limiting nutrient conditions in Lake Naivasha, Kenya
}

\author{
Josephine Njambuya $\cdot$ Ludwig Triest
}

Published online: 14 September 2010

(C) Springer Science+Business Media B.V. 2010

\begin{abstract}
The ability of Ludwigia stolonifera to thrive in the presence of Eichhornia crassipes was investigated in Lake Naivasha, Kenya. L. stolonifera (indigenous) and $E$. crassipes (invasive alien) were grown in outdoor experimental boxes in monocultures and mixtures under non-limiting nutrient conditions. An additive series design with eight combinations of planting densities and four replicates was used. Competitive interactions between the two species were determined by assessing the final total biomass and above-below-ground biomass allocation after 98 days of growth. Biomass accumulation and allocation were significantly affected by competition in relation to species, with $L$. stolonifera accumulating more biomass than E. crassipes. ANOVA analysis indicated that there was no significant difference in Relative Growth Rate (RGR) and root/shoot ratio between monocultures and mixtures with $E$. crassipes. However, significant differences in RGRs were
\end{abstract}

Guest editors: A. Pieterse, S. Hellsten, J. Newman, J. Caffrey, F. Ecke, T. Ferreira, B. Gopal, J. Haury, G. Janauer, T. Kairesalo, A. Kanninen, K. Karttunen, J. Sarvala, K. Szoszkiewicz, H. Toivonen, L. Triest, P. Uotila, N. Willby / Aquatic Invasions and Relation to Environmental Changes: Proceedings of the 12th International Symposium on Aquatic Weeds, European Weed Research Society

J. Njambuya $(\bowtie) \cdot$ L. Triest

Plant Science and Nature Management (APNA), Vrije Universiteit Brussels, Pleinlaan 2, 1050 Brussels, Belgium e-mail: jnjambuy@vub.ac.be observed between monocultures and mixtures of L. stolonifera. Multiple regressions on species RGRs revealed that increasing initial biomass of a conspecific neighbour resulted to a greater reduction in species RGR in relation to increasing initial biomass of a hetero-specific neighbour. Thus, a stronger intrathan inter-specific competition coupled with the significantly higher RGR of $L$. stolonifera relative to that of E. crassipes enabled L. stolonifera to outperform E. crassipes.

Keywords Eichhornia - Ludwigia . Outcome of competition - Species identity - Species influence . Biomass composition

\section{Introduction}

Lake Naivasha is a shallow freshwater lake in Kenya's Rift Valley, situated $80 \mathrm{~km}$ northwest of Nairobi and $190 \mathrm{~km}$ south of the equator at an elevation of $1890 \mathrm{~m}$ above sea level. The lake normally has a surface area of $150 \mathrm{~km}^{2}$, but this can shrink to $100 \mathrm{~km}^{2}$ due to changes in annual rainfall coupled with high evapotranspiration rates (Harper et al., 1995) as well as the effects of other climatic changes that affect the catchment (Vincent et al., 1979). Lake Naivasha, like many other tropical African lakes, has been colonized by exotic species. Although it became a Ramsar site in 1995, its limnology and productivity are threatened by human activity (Harper \& Mavuti, 2004). In the last 
two decades, intensive horticulture has accelerated papyrus clearance (Boar et al., 1999) by drainage and application of fertilizer. The lake is now considered moderately eutrophic (Kitaka et al., 2002) because of agricultural development in the catchment area as well as on the lakeshore. In addition, the lake has a long history of introduction of alien species, including fish, mammals, plants and invertebrates since the 1920s (Harper et al., 1990; Harper \& Mavuti, 2004). These changes have affected aquatic plant species composition and abundance (Harper, 1992) as well as phytoplankton biomass (Hubble \& Harper, 2002; Ballot et al., 2009). While some of the alien species in Lake Naivasha were introduced intentionally, such as the alien Louisiana red swamp cray fish, Procambarus clarkii Girard (Crustacea, Decapoda), which was introduced as an additional species for fishing, others were accidental arrivals. These include the invasive alien carp (Cyprinus carpio L.), South America mammal coypu, Myocastor coypus Molina, water hyacinth (Eichhornia crassipes (Mart.) Solms (Pontederiaceae), 'Kariba weed', the aquatic fern (Salvinia molesta D.S. Mitchell [S. auriculata auct.] (Salviniaceae) and the water lettuce, Pistia stratiotes L. (Araceae). All these alien species have had considerable effects on the native biodiversity of the Lake. For example, the decline of native rooted submerged and floating leaved plants in 1982/1983 was mainly attributed to herbivory by the alien Procambarus clarkii and partly to competitive exclusion by Salvinia molesta (Harper, 1992). In addition, the observed reduction in the population of Nymphaea caerulea Savign. from the late 1970 s was partially attributed to Myocastor coypus (Harper, 1992).

Eichhornia crassipes first arrived in Lake Naivasha in 1988, recorded as isolated plants in the northern shallows (Harper et al., 1995). Surveys conducted after the first record indicates that cover has increased and remained stable compared to other alien plants in Lake Naivasha (Adam et al., 2002). Currently, water hyacinth dominates and is more frequent than other alien species (Ngari et al., 2008). E. crassipes has the potential to grow and disperse rapidly (Cook, 1990). It can quickly increase to very high densities (over $60 \mathrm{~kg} \mathrm{~m}^{-2}$ ) completely clogging water bodies, which in turn may have negative effects on the environment, human health and economic development (Fernández et al., 1990; Epstein, 1998; LVEMP, 1999; Mailu, 2001). Due to the density of these mats, light penetration and oxygen beneath are reduced, impacting submerged vegetation. By releasing allelochemicals (Sun et al., 1993; Sharma et al., 1996), E. crassipes antagonizes the growth of other organisms and reduces biodiversity (Masifwa et al., 2001; Brendonck et al., 2003). Nevertheless, reports of a diverse associated fauna are often found (Gopal, 1987; Barreto \& Evans, 1996; Dibble et al., 1996; Evans \& Reeder, 2001; Masifwa et al., 2001) as well as a diverse floral community (Adam et al., 2002).

The littoral zone of Lake Naivasha is dominated by floating plants of E. crassipes in shallow water and rooted plants on the shore edge, and interactions with vegetation in the littoral zone are inevitable. The large floating mats of E. crassipes offer opportunities for colonization by other herbaceous plants and shrubs. The most common native macrophyte is Ludwigia stolonifera (Guill. \& Perr.) P. H. Raven (Adam et al., 2002), which is a creeping emergent member of the Onagraceae and often co-occurs with E. crassipes. Impacts of alien plant species on native flora in Lake Naivasha have mainly been assessed by field observations and no garden experiments that mimic field conditions have been conducted as far as we know. However, even small-scale experiments can provide valuable information that can be used to quantify the extent to which individuals of co-occurring species affect and respond to each other and how these interactions influence on the structure of plant community. Experimental systems have historically informed understanding of ecological processes applicable at larger scales. They provide a means of conducting ecosystem-level experiments under replicated, controlled, and repeatable conditions (Kemp et al., 1980; Odum, 1984), and have therefore become widely used and accepted tools in ecology (Ives et al., 1996). However, artifacts related to reduced sizes, enclosure and scaling effects may limit our ability to relate small-scale experiment to natural systems (Schindler, 1987; Carpenter, 1996; Petersen et al., 1997). Therefore, the extent and generalization from small-scale experiments to field conditions cannot be done without much care.

In this study, we compared the performance of E. crassipes relative to L. stolonifera both in monocultures and mixtures with the aim of revealing the interactive effects of E. crassipes and L. stolonifera on their respective growth rates and determine the role of species identity, influence and initial 
abundance in structuring the biomass composition of the two species in a mixture.

\section{Materials and methods}

\section{Experimental design}

The material for growing experiment was collected from a cut off channel of Lake Naivasha where they were found growing concurrently. The growing experiments were conducted at the Kenya Agricultural Research Institute, Naivasha station. The two species were grown both in monoculture and mixture in outdoor galvanized boxes measuring $30 \times 30 \times$ $10 \mathrm{~cm}$ for 98 days under ambient conditions. We used apical shoots of $10 \pm 2 \mathrm{~cm}$ for L. stolonifera and a young shoot (daughter plant) with maximum three leaves for E. crassipes. To mimic conditions at the littoral zone where both plants are found in shallow waters, volcanic pumice was used as a substrate. This was amended with $25 \mathrm{~g}$ of commercial organic fertilizer per $15 \mathrm{~kg}$ of fine volcanic pumice to ensure non-limiting nutrient conditions during growth period. Water from River Malewa, which is the main inlet into the lake, was used throughout the growth period.

The experimental design followed an addition series (Spitters, 1983) consisting of factorial combinations of different densities of the two competing plant species. The ratio of $E$. crassipes to $L$. stolonifera planting densities were 0:2, 0:4, 2:0, 4:0, 2:2, 2:4, 4:2, 4:4 in different boxes, equivalent to total densities from 22 to 88 plants $\mathrm{m}^{-2}$ at the start of the experiment. Each density treatment had five replicates resulting to a total of 40 boxes. These were placed randomly in open space to minimize localized effects. After 98 days of growth, all plants were harvested and cleaned to remove the sediment and separated into species. For each species, the above-ground (shoots) and below-ground (roots) parts were separated and dried to a constant weight at $70^{\circ} \mathrm{C}$. Due to the growth mode of L. stolonifera, it was impossible to separate individual plants and therefore, total biomass, shoot and root biomass for each species were measured per stand rather than per individual plants and hence all statistical analysis on a species was done at a stand level. The initial biomass was measured by randomly sampling 25 individuals per species from which five random individuals were averaged to represent the initial biomass of a single shoot for each of the five replicates. The total initial biomass per stand per species was then estimated by multiplying the dry weight of a single shoot of a species with the initial number of shoots planted per stand. Therefore, a species total initial biomass per stand varied according to the initial planting densities.

\section{Data analysis}

We assessed the growth performance of $E$. crassipes and L. stolonifera by total final biomass, shoot and root mass fraction, shoot to root ratio and species average relative growth rate (RGR). Preliminary analysis for the differences between monocultures and mixtures were done using one-way ANOVA in normally distributed data and Kruskal-Wallis ANOVA in non-normally distributed data. RGR for $i$ th species (for $i=$ species 1 or 2) was calculated according to Connolly \& Wayne (1996) as;

$\mathrm{RGR}_{i}=\ln \left(Y_{i} / y_{i}\right) / t$

where $Y_{i}$ is the species stand biomass at the end of the experimental period, $y_{i}$ is the species stand biomass at the beginning of the experimental period, $t$ is the duration of the experiment and $\ln$ is the natural logarithm.

Species competitive interaction and their effect on species performance were assessed using multivariate analysis. We performed multiple regressions on various measures of performance, that are: species total biomass, root and shoot biomasses, species average RGR and the species relative growth rate difference (RGRD) with species initial biomass (centred) as the regressing variable. Linear equation for species average RGR, final total biomass, final root and shoot biomass and root to shoot ratio were defined as follows; For a species $i$ in mixture with species $j$ :

$Y_{i}=a_{i 0}+a_{i i} y_{i}+a_{i j} y_{j}$

The corresponding equation for species $j$ in mixture with species $i$ :

$Y_{j}=a_{j 0}+a_{j i} y_{i}+a_{j j} y_{j}$

where $a_{i i}$ and $a_{i j}$ is the intra- and inter-specific effects on $Y_{i}$ while $a_{j j}$ and $a_{j i}$ is the intra- and inter-specific 
effects on $Y_{j}$. The constant $a_{i 0}$ and $a_{j 0}$ measures the constant change in $Y_{i}$ and $Y_{j}$, respectively. $Y$ is the species performance measure being regressed, while $y_{i}$ and $y_{j}$ are the stand initial biomass of species $i$ and $j$ (for $i$ equals $L$. stolonifera and $j$ equals E. crassipes).

Other than determining species performance and the effects of intra- and inter-specific effects on a species performance, change in biomass composition of these two species in mixture was also investigated using the RGRD model for two species in mixture by Connolly \& Wayne (2005). Stand biomass composition changes over time, if one species in a mixture is gaining at a faster per unit rate than another. Thus, such a species will be more abundant and hence its final relative proportion in a stand will increase. Otherwise, if all species gain at the same rate, the stand composition in terms of proportional abundance of species will remain the same. The change in biomass composition is therefore as a result of difference in average relative growth rate between species in a mixture. Connolly \& Wayne (2005) argue that the difference in average relative growth rate between species is determined by various factors acting either separately or jointly. Their model (Eq. 4) mainly focuses on three factors and these include: (1) the constant difference in average relative growth rate between species (species identity), (2) the difference between a species intraspecific effects on its own RGR and its inter-specific effects on RGR of the other species (species influence) and (3) environmental variables (Treatment). The effects of these three factors are well separated in the model. We modelled RGRD (RGR LudwigiaRGR Eichhornia) as follows;

$\mathrm{RGRD}_{12}=b_{0}+b_{1} y_{1}+b_{2} y_{2}+b_{3} T+\varepsilon$

where $b_{1}$ and $b_{2}$ (for 1 equals L. stolonifera and 2 equals $E$. crassipes) measure the effects of changing the initial biomass of species 1 or 2 on RGRD. A positive value of $\mathrm{b}_{i}$ (for $i=1$ or 2) indicates that an increase in $i$ th species biomass in the initial community will enhance the RGRD in favour of species 1 , and hence will tilt the final composition more towards that species. A negative value has the opposite effect. The two coefficients $b_{1}$ and $b_{2}$, also referred to as influence coefficients (Ramseier et al., 2005) reveal how changes in initial abundance of the species can influence the growth differential between species. $b_{3}$ measures the effects of applied treatment (denoted by variable $T$ ) but in this experiment it was scaled to zero since no treatment was applied. If all the coefficients $\left(b_{1}, b_{2}, b_{3}\right)$ are zero then RGRD is not affected by the initial composition or applied treatment and will be constant $\left(b_{0}\right)$. This constant difference in average RGR reflects the differences in RGR of the two species over the growth period and will shift stand composition towards the faster growing species. In case $b_{\mathrm{o}}$ is also zero, community composition will not change over the experimental period.

This model offers readily available testable hypotheses that are relevant in competition studies. In addition, the model only requires information on initial and final biomass or other measures of performance in order to be implemented. This is unlike the classical competition models, for example, the reciprocal yield model of Wright (1981) and later Spitters (1983) that requires the knowledge of individual plant weight. The RGRD model is useful in plants that exhibit clonal growth form and also at time when it is impossible to separate individual plants in a stand due to their growth form; a situation that is evident for L. stolonifera.

\section{Results}

Species RGR, biomass accumulation and allocation

Generally, L. stolonifera accumulated more total biomass than $E$. crassipes in all density combinations studied here (Fig. 1). Averaged over all stands, in L. stolonifera, the total biomass output per unit input was four times that of E. crassipes. Thus, the species mean RGR of 0.036 /day was significantly higher than $0.022 /$ day of $E$. crassipes $\left(t_{(2,16)}=P<0.0001\right)$. A comparison between monocultures and mixtures shows that $L$. stolonifera performed better in monocultures than in mixtures, while the opposite was true for E. crassipes (Fig. 1). However, analysis of variance did not reveal significant differences between monoculture and mixture of either species but significant differences among density treatment was evident in both species (L. stolonifera; KruskalWallis ANOVA, $P=0.0001$ and E. crassipes; ANOVA, $P<0.0001)$. 


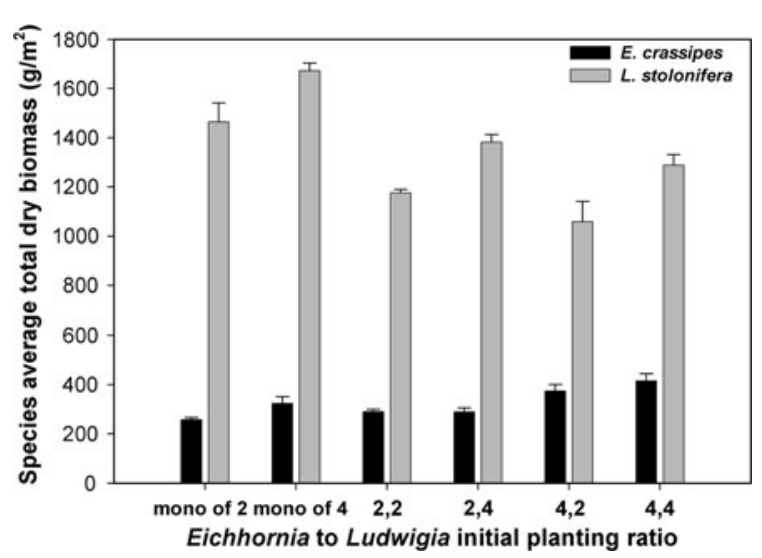

Fig. 1 Average total dry biomass $\left(\mathrm{g} \mathrm{m}^{-2}\right)$ for L. stolonifera and E. crassipes grown in different densities over the experimental period Monos refers to monocultures. Error bars represent $\pm \mathrm{SE}$ of the means

On root-to-shoot ratio, both species allocated more biomass on aboveground relative to belowground parts (Fig. 2). ANOVA on root/shoot ratio between monocultures and mixtures of E. crassipes were not significant $(P>0.05)$. However, a comparison between monocultures and mixtures of $L$. stolonifera showed a significant allocation to root relative to shoot biomass when the initial density of E. crassipes was twice that of L. stolonifera (Kruskal-Wallis ANOVA $P=0.03$ ). L. stolonifera accumulated more shoots and roots than E. crassipes and consequently would be expected to have a higher shoot mass

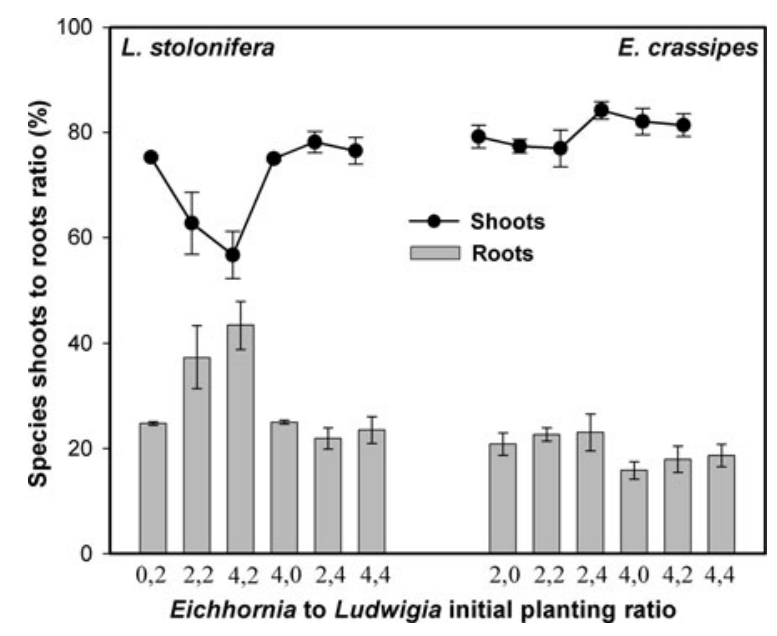

Fig. 2 Shoots to roots ratio (in percentages) for L. stolonifera and $E$. crassipes grown in different densities over the experimental period. Error bars represent \pm SE of the means ratio and root mass ratio (Mann-Whitney $U$ test $P<0.0001)$.

Species response to a neighbour

The response of each species total biomass, shoot biomass, root biomass and RGR to a con-specific and/or hetero-specific neighbour were described in linear equation (Table 1). A negative coefficient indicates a decrease in the variable regressed as a result of increasing initial biomass of a species $\left(y_{1}\right.$ or $y_{2}$ ), while a positive coefficient indicates the opposite.

The two species responded differently when they are in competition with either a con-specific or hetero-specific neighbour. The RGR of L. stolonifera was significantly suppressed by both con-specific and hetero-specific neighbours. Increasing the initial biomass of both species reduced the species RGR which is an indication of strong intra- and interspecific competition. The RGR of E. crassipes, however, increased with increasing initial density and biomass of L. stolonifera but decreased with increasing of its own initial density and biomass, an indication of both facilitation and suppression processes. However, both species experienced stronger intra- than inter-specific effects on their RGR as demonstrated by the magnitude of the competition coefficient (Table 1). The total biomass and shoot biomass of $L$. stolonifera were significantly enhanced by increasing initial biomass of its own but increasing initial biomass of $E$. crassipes had the opposite effect. L. stolonifera root biomass increased with increasing initial biomass of E. crassipes, but this effect was not significant (Table 1). In the case of E. crassipes, increasing initial biomass of both species significantly enhanced the species total biomass due to higher shoot biomass. Similarly, increasing both species initial biomass had facultative effects on the species root biomass, although only the influence of L. stolonifera was significant (Table 1).

\section{Determinant of change in biomass composition}

The relative growth rate difference (RGRD) model showed a significant change in biomass composition of the two species in mixture over the growth period (Table 1). The overall significance of the constant showed there was a large difference between the average RGR of the species. The effect of initial 
Table 1 Linear equations for plant relative growth rate, total biomass, shoot biomass, root biomass and relative growth rate difference (RGRD) between L. stolonifera and E. crassipes over the growth period

\begin{tabular}{llll}
\hline Species & Variable & Linear models & $R^{2}$ \\
\hline L. stolonifera & RGR & $Y=\mathbf{0 . 0 3 5 7}-\mathbf{0 . 0 0 2 3} y_{1}-\mathbf{0 . 0 0 0 5} y_{2}$ & $0.96 * * *$ \\
& Total biomass & $Y=\mathbf{1 1 0 . 5 9 1 6}+\mathbf{1 0 . 0 7 4 9} y_{1}-\mathbf{4 . 2 1 3 1} y_{2}$ & $0.67 * * *$ \\
& Shoot biomass & $Y=\mathbf{7 8 . 7 1 9 9}+\mathbf{9 . 7 0 9 2} y_{1}-\mathbf{6 . 8 5 1 0} y_{2}$ & $0.92^{* * *}$ \\
& Root biomass & $Y=\mathbf{4 . 5 5 1 4}-2.5976 y_{1}+0.0053 y_{2}$ & $0.11^{\text {NS }}$ \\
RGR crassipes & $Y=\mathbf{0 . 0 2 2 7}+\mathbf{0 . 0 0 0 4} y_{1}-\mathbf{0 . 0 0 2 0} y_{2}$ & $0.80^{* * *}$ \\
& Total biomass & $Y=\mathbf{2 8 . 9 1 8 7}+\mathbf{0 . 9 0 1 4} y_{1}+\mathbf{2 . 0 8 9 1} y_{2}$ & $0.56 * * *$ \\
& Shoot biomass & $Y=\mathbf{2 3 . 4 5 2 3}+\mathbf{0 . 7 3 8 4} y_{1}+\mathbf{2 . 3 4 5 5} y_{2}$ & $0.58 * * *$ \\
& Root biomass & $Y=\mathbf{5 . 4 6 0 7}+\mathbf{0 . 2 0 1 0} y_{1}+0.0336 y_{2}$ & $0.25 *$ \\
& RGRD & $Y=\mathbf{0 . 0 1 2 6}-\mathbf{0 . 0 0 2 4} y_{1}+\mathbf{0 . 0 0 1 5} y_{2}$ & $0.83 * * *$ \\
\hline
\end{tabular}

In bold are significant values at $t$ statistic greater than 2. $y_{1}$ is initial biomass of L. stolonifera, $y_{2}$ is initial biomass of E. crassipes NS not significant

Asterisk indicates the degree of significance of $R^{2}$ value; $* P<0.05$, ** $P<0.01$, *** $P<0.001$

stand biomass is judged by the size of the influence coefficients: these were significant but are smaller relative to those of the constant (species identity) and hence they only had minor influences (Table 1). Increasing the initial biomass of L. stolonifera reduced the difference in average RGR between the two species in favour of E. crassipes. This is indicated by the negative coefficient on initial biomass of L. stolonifera $\left(y_{1}\right)$. E. crassipes had the

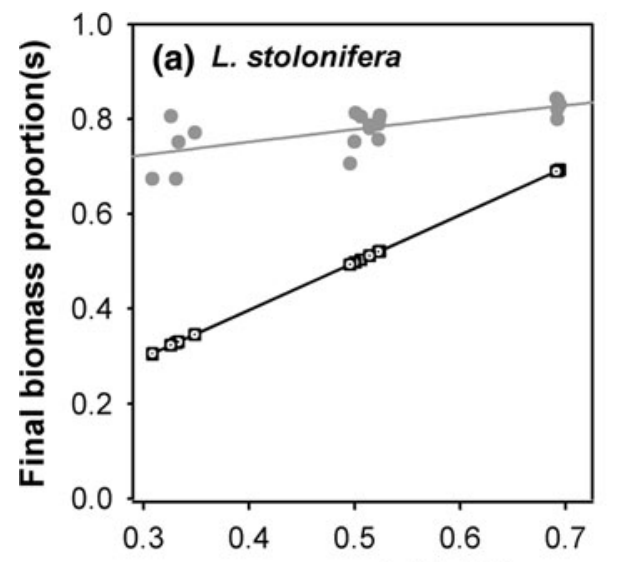

Fig. 3 Change in species final relative to initial biomass proportional abundance (dry weight) for a L. stolonifera and b E. crassipes in mixtures. The proportion of a species initial/ final dry biomass is a function of its initial/final dry weight divided by stand total initial dry biomass. No change in species

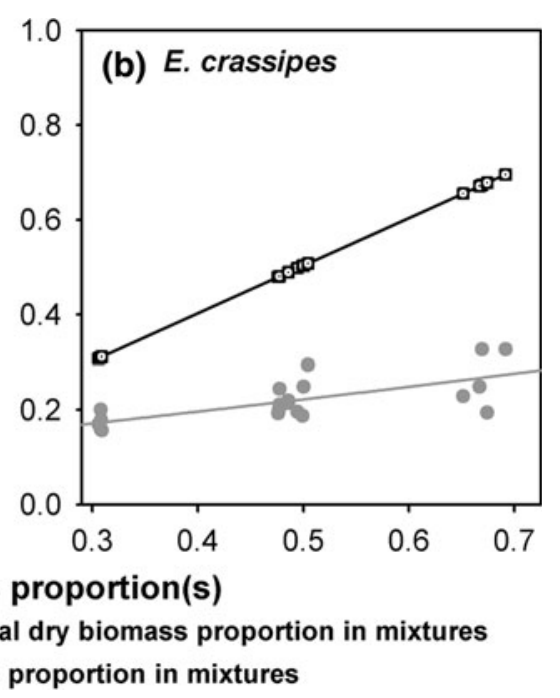

opposite effects on RGRD as indicated by the influence coefficient $\left(y_{2}\right)$ (Table 1).

Change in species final biomass composition

The stands final biomass composition was largely dominated by L. stolonifera relative to E. crassipes with $L$. stolonifera final biomass proportion being greater than 0.65 (Fig. 3a, b) in all mixtures. The

initial biomass proportional abundance refers to a scenario where the initial biomass proportion of a species in mixture remain the same till the end of the experiment due to species equal gain per unit rate $(\mathrm{RGRD}=0$ ), while change (gain or loss) is the deviation from the No change curve 
relative gain in final relative to initial biomass proportion by $L$. stolonifera was mainly driven by the significantly higher growth rate of the species compared to that of E. crassipes. The RGRD model indicates that the difference between these two species average RGR in mixture (species identity) was highly significant (Table 1). However, the change in composition was not solely due to species identity but also due to significant effects of intraand inter-specific species interactions (species influence) (Table 1). Our results indicated that there is a stronger intra- than inter-specific effects on species RGR. These two factors enhanced the performance of L. stolonifera relative to E. crassipes. Thus the shift in final biomass proportion relative to initial proportion was more towards L. stolonifera. The shift was more pronounced at low than high initial biomass proportion in both species (Fig. 3a, b).

\section{Discussion}

\section{Biomass production and RGR}

There is a general perception that invaders are better competitors than native species (Baker, 1965; Newsome \& Noble, 1986; Vilà \& Weiner, 2004) and that invasive species often have high growth rate that allows them to outperform native species (Cronk $\&$ Fuller, 1995). On the contrary, our results showed that the native species outperformed the invasive species in all measures of performance studied here under nutrient non-limited conditions. These findings are consistent with the conclusion drawn by Daehler (2003) that invasive species do not always have higher growth rate and neither do they often competitively outperform co-occurring native species. Some native species have the same attributes as invasive species (Thompson et al., 1995). In this study, L. stolonifera, a "creeping emergent" macrophyte, had a higher average RGR, constantly accumulated more biomass (total biomass, shoot biomass, root biomass) and had a higher root to shoot mass ratio than the invasive species. Rapid growth rate and high accumulation of total biomass has been demonstrated in other plant species that exhibit 'creeping emergent' growth mode. In addition, this group of species accumulates more biomass to above than belowground parts (Rejmánková, 1992). Reducing biomass allocation to belowground parts means increasing biomass allocation to aboveground parts, that is, leaves, stems, branches and petioles, all which can fix $\mathrm{CO}_{2}$ through photosynthesis (Cernusak \& Marshall, 2000), contributing to carbon fixation required for rapid growth.

The performance of $L$. stolonifera can be explained mainly by its species identity. Our results indicated that L. stolonifera had a constantly higher average relative growth rate and the RGRD between the two species was significantly different from zero. The ability of some plant species to achieve higher RGR than others is driven by mechanisms related to plant's physiology, morphology and biomass allocation (Pugnaire \& Valladares, 2007). L. stolonifera exhibited intense vegetative growth and rapid clonal expansion and this has been reported in other Ludwigia species (Rejmánková, 1992; GIS Macrophytes, 1997; Muller, 2000). Rapid growth rate has an ecological advantage in that the faster growing species is able to quickly occupy the available space within the vegetation thereby preempting space, which would otherwise be available for other species (Grime \& Hunt, 1975). By merit of occupying a larger space, such species have an advantage in terms of resources acquisition both above and below ground as this depends on how much of the volume of soil and air is occupied by roots and leaves (Pugnaire \& Valladares, 2007). In competitive situation, the species with higher RGR is deemed to be more efficient over the course of the experiment in the sense that it has a higher output per unit input (Connolly \& Wayne, 2005). Therefore, such a species is able to dominate an area quickly and becomes the most dominant species. In species that exhibit clonal growth such as L. stolonifera and E. crassipes, rapid clonal expansion is a mean by which a species is able to colonize, occupy and pre-empty space. This depends on the dynamics of clonal growth and expansion (Doust, 1981) and varies among species.

Clonal plants often show two types of clonal expansion strategies, 'phalanx' versus 'guerilla'. The "guerilla" strategy maximizes horizontal expansion of the plant genet by increasing the distance between ramets whiles the 'phalanx' strategist spaces modular unit close to one another (Doust, 1981). Clonal plants with a "guerrilla" strategy, vegetative propagation of rhizomes, stolons, and adventitious roots is interpreted as a mechanism promoting rapid growth, spatial exploration, resource acquisition, and escape 
from competition (Doust, 1981; Fahrig et al., 1994). Although both species are stoloniferous and exhibited "guerrilla-type" of clonal expansion, the species clearly differed in the rate of branching and spacing of inter-grown ramets. In E. crassipes, new shoots were formed only at the end of elongated stolons, whereas L. stolonifera exhibited an intense branching growth pattern often developing new shoots that quickly infiltrated to the surrounding empty spaces. This rapid and extensive development of shoot (both prostrate and ascending) by L. stolonifera enabled the species to quickly usurp space thereby overcrowding E. crassipes. Furthermore, the more spatial species rooting mode at every node could have enhanced nutrient uptake relative to E. crassipes. Nevertheless, E. crassipes was observed to perform slightly better in mixture than in monoculture as reported by Agami \& Reddy (1991).

Determinant of change in species biomass composition

Connolly \& Wayne (2001) have focused attention on the relative importance of species identity, species influence and environment as determinants of species' gain and hence change in stand biomass composition. In our experiment, we observed large differences in average RGR between the two species. Species identity was therefore the main determinant of change in biomass composition of these two species in mixture. In addition, species influence had significant effects but these were of lesser magnitude compared to species identity. According to Connolly \& Wayne (2005), the large differences in RGR (species identity) observed in our experiment, would by themselves lead to considerable change in species' relative abundance in mixture, as they are much the strongest element in modifying structure. The importance of species identity relative to intraand inter-specific competition in structuring community final biomass has also been reported in other studies (Connolly \& Wayne, 2005; Ramseier et al., 2005; Suter et al., 2007).

Change in species final biomass proportional abundances

The change in proportional abundances of two species in mixture over the duration of experiment is related to a difference in their RGR. If all species gain at the same per unit rate, stand composition, defined as the proportional abundances of species, will remain unchanged, while if one species gains at a faster per unit rate than another, its relative proportion in the community will increase (Connolly \& Wayne, 2005). In this study, L. stolonifera had a higher constant growth rate and hence the species always increased its final proportion irrespective of its relative abundance at the start while E. crassipes proportion was always reduced. This ability of L. stolonifera to gain more biomass than E. crassipes irrespective of its initial abundance resulted to its dominance and hence the shift in final stands biomass composition more towards L. stolonifera. Changes in species relative abundance have often been attributed to inter-specific competition (e.g., Reader et al., 1994; Peltzer \& Köchy, 2001), but our results indicated that this was not independent of intra-specific effects. The stronger intra- than inter-specific effects had a significant influence on both species performance, and these effects were more pronounced at high initial biomass of either species. Being present in high initial abundance, each species' own performance was more reduced than when in low initial abundance. The stronger intra- than inter-specific competition has been reported by many other studies (e.g. Suter et al., 2007; Johansson \& Keddy, 1991). However Huckle et al., (2002) found the reverse pattern while (Aguiar et al., 2001) found equal strength of intra- and inter-specific competition.

\section{Abundance of L. stolonifera in Lake Naivasha}

The results of this experiment have shown that the growth characteristics and performance of $L$. stolonifera are not any different from those of its related species. Several Ludwigia species are invasive and have been reported to have great impacts on ecosystems they invade due to their rapid growth rate that often result to dense mats (Sheppard et al., 2006). In this experiment, L. stolonifera outperformed and dominated E. crassipes over the growth period. However, despite this great performance, L. stolonifera remains largely inconspicuous in open water and unsheltered bays in Lake Naivasha but dominate in the more edgy part of the littoral zone. Based on the outcome of this experiment, we conclude that the effect of E. crassipes on L. stolonifera is probably 
wind mediated. The lake is wind-stressed and consequently, the prevailing winds have been described as very important physical factor influencing lake's physical, chemical and biological functions (TarrasWahlberg, 1975). Wind is one of the most important environmental parameter that greatly influences the distribution and abundance of macrophytes in Lake Naivasha (Ngari et al., 2008). The wind continuously aid in translocation of large floating mats of Eichhornia that could be responsible for physically smothering and displacing native macrophytes at the lakeshore where they drift. Other than probable displacement, competition from erect emergent could be affecting the performance of $L$. stolonifera at the lakeshore. Erect emergent have been reported to slowly out-compete creeping macrophytes especially in undisturbed environment (Rejmánková, 1992). These factors among others could be impacting on performance of L. stolonifera in Lake Naivasha.

Acknowledgments We thank Kenya Agricultural Research Institute (KARI) for allowing us to set this experiment at their research centre in Naivasha, to KARI Naivasha staff for their assistance in technical and logistic issues during the entire experimental period. Thanks are due to the two anonymous reviewers and editors for helpful comments on an earlier version of the manuscript. This study was funded by a $\mathrm{PhD}$ grant of the Vrije Universiteit Brussel (VUB-BOW Scholarship).

\section{References}

Adam, C. S., R. R. Boar, D. S. Hubble, M. Gikungu, D. M. Harper, P. Hickley \& N. Tarras-Wahlberg, 2002. The dynamics and ecology of exotic tropical floating plants mats: Lake Naivasha, Kenya. Hydrobiologia 488: 115-122.

Agami, M. \& K. R. Reddy, 1991. Interrelationships between Eichhornia crassipes (Mart.) Solms and Hydrocotyle umbellata L. Aquatic Botany 39: 147-157.

Aguiar, M. R., W. K. Lauenroth \& D. P. Peter, 2001. Intensity of intra- and interspecific competition in coexisting shortgrass species. Journal of Ecology 89: 40-47.

Baker, H. G., 1965. Characteristics and modes of origin of weeds. In Baker, H. G. \& G. L. Stebbins (eds), The Genetics of Colonizing Species. Academic Press, New York: 147-172.

Ballot, A., K. Kotut, E. Novel \& L. Krienitz, 2009. Changes of phytoplankton community in Lake Naivasha and Oloidien, examples of degradation and salinization of Lakes in the Kenyan Rift Valley. Hydrobiologia 632: 359-363.

Barreto, R. W. \& H. C. Evans, 1996. Fungal pathogens of some Brazilian aquatic weeds and their potential use in biocontrol. In Moran, V. C. \& H. Hoffmann (eds), Proceedings of the IX International Symposium on Biological Control of Weeds, Stellenbosch, South Africa: 121-126.
Boar, R. R., D. M. Harper \& C. S. Adams, 1999. Biomass allocation in Cyperus papyrus in Tropical Wetland, Lake Naivasha, Kenya. Biotropica 31: 411-421.

Brendonck, L., J. Maes, W. Rommens, et al., 2003. The impact of water hyacinth (Eichhornia crassipes) in a eutropic subtropical impoundment (Lake Chivero, Zimbabwe). II. Species diversity. Fundamental and applied limnology. Archiv fur Hydrobiologie 158: 389-405.

Carpenter, S. R., 1996. Microcosm experiments have limited relevance for community and ecosystem ecology. Ecology 77: 667-680.

Cernusak, L. A. \& J. D. Marshall, 2000. Photosynthetic refixation in branches of western white pine. Functional Ecology 14: 300-311.

Connolly, J. \& P. Wayne, 1996. Asymmetric competition between plant species. Oecologia 108: 311-320.

Connolly, J. \& P. Wayne, 2005. Assessing determinants of community biomass composition in two-species plant competition studies. Oecologia 142: 450-457.

Cook, C. D., 1990. Origin, autoecology and spread of some of the world's most troublesome aquatic weeds. In Pieterse, A. H. \& K. J. Murphy (eds), Aquatic Weeds: The Ecology and Management of Nuisance Aquatic Vegetation. Oxford University Press, Oxford: 31-38.

Cronk, Q. C. B. \& J. L. Fuller, 1995. Plant Invaders. Chapman \& Hall, New York.

Daehler, C. C., 2003. Performance comparison of co-occurring native and alien invasive plants: implications for conservation and restoration. Annual Review of Ecology Evolution and Systematics 34: 183-221.

Dibble, E. D., K. J. Killgore \& G. O. Dick, 1996. Measurement of plant architecture in seven aquatic plants. Journal of Freshwater Ecology 11: 311-318.

Doust, L. L., 1981. Population dynamics and local specialization in a clonal perennial (Ranunculus repens): I. The dynamics of ramets in contrasting habitats. Journal of Ecology 69: 743-755.

Epstein, P., 1998. Weeds bring disease to the east African waterways. Lancet 351: 577.

Evans, H. C. \& R. H. Reeder, 2001. Fungi associated with Eichhornia crassipes (water hyacinth) in the upper Amazon Basin and prospects of their use in biological control. In Biological and Integrated Control of Water Hyacinth, Eichhornia crassipes. Proceedings of the Global Working Group for the Biological Control and Integrated Control of Water Hyacinth, Beijing, China. ACIAR Proceedings No 102: 62-70.

Fahrig, L., D. P. Coffin, W. K. Lauenroth \& H. H. Shugart, 1994. The advantage of long-distance clonal spreading in highly disturbed habitats. Evolutionary Ecology 8: 172-187.

Fernández, O. A., D. L. Sutton, V. H. Lallana, M. R. Sabbatini \& J. H. Irigoyan, 1990. Aquatic weeds problems and management in South and Central America. In Pieterse, A. H. \& K. J. Murphy (eds), Aquatic Weeds: The Ecology and Management of Nuisance Aquatic Vegetation. Oxford University Press, Oxford: 406-425.

GIS Macrophytes, 1997. Biologie et écologie des espéces végé -tales aquatiques proliférant en France. Synthése biblio. Rapport réalisé à la demande de l'Inter-Agence de l'eau 68: 199 pp. 
Gopal, B., 1987. Aquatic plant studies I. Water hyacinth. Elsevier publishing, New York.

Grime, J. P. \& R. Hunt, 1975. Relative growth-rate: its range and adaptive significance in a local flora. Journal of Ecology 63: 393-422.

Harper, D. M., 1992. The ecological relationships of aquatic plants at Lake Naivasha, Kenya. Hydrobiologia 232: 65-71.

Harper, D. M. \& K. M. Mavuti, 2004. Lake Naivasha, Kenya: Ecohydrology to guide the management of a tropical protected area. International Journal of Ecohydrology and Hydrobiology 4: 287-305.

Harper, D. M., K. M. Mavuti \& S. M. Muchiri, 1990. Ecology and management of Lake Naivasha, Kenya, in relation to climatic change, alien species introductions and agricultural development. Environmental Conservation 17: 328-336.

Harper, D. M., C. S. Adam \& K. M. Mavuti, 1995. The aquatic plant communities of Lake Naivasha wetlands, Kenya: pattern, dynamics and conservation. Wetlands Ecology and Management 3: 111-123.

Hubble, D. S. \& D. M. Harper, 2002. Phytoplankton community structure and succession in the columns of Lake Naivasha, Kenya: a shallow tropical lake. Hydrobiologia 488: 89-98.

Huckle, J. M., R. H. Marrs \& J. A. Potter, 2002. Interspecific and intraspecific interactions between salt marsh plants: integrating the effects of environmental factors and density on plant performance. Oikos 96: 307-319.

Ives, A. R., J. Foufopoulos, E. D. Klopfer, J. L. Klug \& T. M. Palmer, 1996. Bottle or big-scale studies: how do we do ecology? Ecology 77: 681-685.

Johansson, M. E. \& P. A. Keddy, 1991. Intensity and asymmetry of competition between plants pairs of different degrees of similarity: an experimental study on two guilds of wetlands plants. Oikos 60: 27-34.

Kemp, W. M., M. R. Lewis, F. F. Cunningham, J. C. Stevenson \& W. R. Boynton, 1980. Microcosm, macrophytes and hierarchies: environmental research in Chesapeake Bay. In Giesy, J. P. (ed.), Microcosms in Ecological Research. National Technical Information Service, Springfield: 911-936.

Kitaka, N., D. M. Harper \& K. M. Mavuti, 2002. Phosphorus inputs to Lake Naivasha, Kenya, from its catchment and the tropic state of the lake. Hydrobiologia 488: 73-80.

LVEMP, Lake Victoria Environmental Management Project, 1999. Report of the Second East African Cooperation Ministerial Meeting on Water Hyacinth, August 19, 1999. Report Ref. No. EAC/SR/12/99, AICC, Arusha, Tanzania.

Mailu, A. M., 2001. Preliminary assessment of the social, economic and environmental impacts of water hyacinth in the Lake Victoria basin and the status of control. In Biological and Integrated Control of Water Hyacinth, Eichhornia crassipes. Proceedings of the Global Working Group for the Biological Control and Integrated Control of Water Hyacinth, Beijing, China. ACIAR proceedings No 102: 62-70.

Masifwa, W. F., T. Twongo \& P. Denny, 2001. The impact of water hycanith, Eichhornia crassipes (Mart) Solms on the abundance and diversity of aquatic macroinvertebrates along the shores of northern Lake Victoria, Uganda. Hydrobiologia 452: 79-88.

Muller, S., 2000. Les espéces végétales invasives en France: Bilan des connaissances et propositions d'actions. Revue d'Ecologie-Terre Vie 7: 53-69.

Newsome, A. E. \& I. R. Noble, 1986. Ecological and physiological characters of invading species. In Groves, R. H. \& J. J. Burden (eds), Ecology of Biological Invasions: An Australian Perspective. Australian Academy of Science, Canberra: 1-20.

Ngari, A. N., J. I. Kinyamario, M. J. Ntiba \& K. M. Mavuti, 2008. Factors affecting abundance and distribution of submerged and floating macrophytes in Lake Naivasha, Kenya. African Journal of Ecology 47: 32-39.

Odum, E. P., 1984. The mesocosm. BioScience 34: 558-562.

Peltzer, D. A. \& M. Köchy, 2001. Competitive effects of grasses and woddy plants in mixed-grass prairie. Journal of Ecology 89: 519-527.

Petersen, J. E., C. C. Chen \& W. M. Kemp, 1997. Scaling aquatic primary productivity: Experiments under nutrientand light-limited conditions. Ecology 78: 2326-2338.

Pugnaire, F. I. \& F. Valladares (eds), 2007. Functional Plant Ecology, 2nd ed. CRS Press, Taylor \& Francis Group, Boca Raton, London.

Ramseier, D., J. Connolly \& F. A. Bazzaz, 2005. Carbon dioxide regime, species identity and influence of species initial abundance as determinants of change in stand biomass composition in five-species communities: an investigation using a simplex design and RGRD analysis. Journal of Ecology 93: 502-511.

Reader, R. J., S. D. Wilson, J. W. Belcher, I. Wisheu, P. A. Keddy, D. Tilman, E. C. Morris, J. B. Grace, J. B. McGraw, H. Olff, R. Turkington, E. Klein, Y. Leung, B. Shipley, R. Hulst, M. E. Johannsson, C. Nillson, J. Gurevitch, K. Grigulis \& B. E. Beisner, 1994. Plant competition in relation to neighbour biomass: an intercontinental study with Poa pratensis. Ecology 75: 1753-1760.

Rejmánková, E., 1992. Ecology of creeping macrophytes with special reference to Ludwigia peploides (H. B. K.) Raven. Aquatic Botany 43: 283-299.

Schindler, D. W., 1987. Detecting ecosystem responses to anthropogenic stress. Canadian Journal of Fisheries and Aquatic Science 44: 6-25.

Sharma, A., M. K. Gupta \& P. K. Singhal, 1996. Toxic effects of leachate of water hyacinth decay on growth of Scenedesmus obliquus (Chlorophyta). Water Resources 30: 2281-2286.

Sheppard, A. W., R. H. Shaw \& R. Sforza, 2006. Top 20 environmental weeds for classical biological control in Europe: a review of opportunities, regulations and other barriers to adoption. Weed Research 46: 93-117.

Spitters, C. J. T., 1983. An alternative approach to the analysis of mixed cropping experiments. 1. Estimation of competition effects. Netherlands Journal of Agricultural Sciences 31: 1-11.

Sun, W. H., S. W. Yu, S. Y. Yang, P. W. Zhao, Z. W. Yu, H. M. Wu, S. Y. Huang \& C. S. Tang, 1993. Allelochemicals from root exudates of water hyacinth. Acta Phytophysiologica Sinica (China) 19: 92-96. 
Suter, M., D. Ramseier \& S. Guesewell, 2007. Convergence patterns and multiple species interactions in a designed plant mixture of five species. Oecologia 151: 499-511.

Tarras-Wahlberg, N., 1975. Facts and Recommendations on the Salvinia-Problem of Lake Naivasha. Report delivered at the Lake Naivasha Riparian Owners Association Annual Meeting, Lake Naivasha, Kenya, March 7, 1975.

Thompson, K., J. G. Hodgson \& T. C. G. Rich, 1995. Native and alien invasive plants: more of the same? Ecography 18: $390-402$.
Vilà, M. \& J. Weiner, 2004. Are invasive plant species better competitors than native plant species? Evidence from pair-wise experiments. Oikos 105: 229-238.

Vincent, C., T. Davies \& A. Beresford, 1979. Recent changes in the level of Lake Naivasha, Kenya, as an indicator of equatorial westerlies over East Africa. Climate Change 2: 175-189.

Wright, J. A., 1981. The analysis of yield-density relationships in binary mixtures using inverse polynomials. Journal of Agricultural Science (Cambridge) 96: 561-567. 